ReVeLe - $\mathrm{n}^{\circ} 2$ - Jan/2011

\title{
SUPLEMENTANDO A MEMÓRIA DE UM HERÓI: A VISITA DE CECÍLIA MEIRELES E DE PEDRO AMERICO AO ARQUIVO DA INCONFIDÊNCIA MINEIRA
}

\author{
Mariana Moreira Fernandes Barata - FALE/UFMG* \\ Maria Luiza Scher Pereira - Fac . de letras/UFJF**
}

\section{A INCONFIDÊNCIA MINEIRA COMO UM ARQUIVO}

Dentre todos os movimentos rebeldes na História Brasileira, a Inconfidência Mineira tem um lugar especial na memória dos brasileiros. Ocorrida no século XVIII, a insurreição suplantou sua temporalidade e marca presença ainda hoje como um episódio memorável no caminho da formação de nossa nacionalidade. Não foram poucos os artistas que a tomaram por tema de suas obras, nem os políticos que se auto-proclamaram imbuídos de seu espírito libertador'. Diante desse cenário, fica a pergunta: qual seria a razão dessa especificidade?

Primeiramente, é necessário apontar a apropriação da Inconfidência Mineira e do ícone que a representa, Tiradentes, bem como suas causas. Segundo Carvalho (2006), a reiteração contínua de elementos ligados à revolta mineira, a partir da Proclamação da República (1889), levou à formação de um imaginário coletivo que sobretudo mitifica a figura de Tiradentes. Esse processo,

\footnotetext{
* Mestranda em Teoria da Literatura pela Universidade Federal de Minas Gerais.

** Professora de Literatura Comparada da Universidade Federal de Juiz de Fora. Projeto de pesquisa Literatura e arquivo: o escritor como leitor, tradutor e produtor de elementos de arquivo.(2007/2010). Proc. 308816/2006-4 CNPq

${ }^{1}$ No primeiro caso, cita-se a peça teatral Gonzaga ou a revolução de Minas (1867) de Castro Alves e o quadro Suplício de Tiradentes (1889) de Francisco Aurélio de Figueiredo e Melo. Já no segundo, aqui faz jus recordar da cerimônia do dia 21 de abril em Minas Gerais. Na data de morte de Tiradentes, o governo estadual transfere a sede do governo por um dia para a cidade e oferece condecorações a figuras ilustres da sociedade mineira, recordando os ideais inconfidentes.
} 
ReVeLe - nº 2 - Jan/2011

evidentemente, teria sofrido infiltrações ideológicas que visavam associar certas posições políticas com a carga simbólica emanada da Inconfidência Mineira, atualizando sempre o passado na perspectiva do presente. Nessa sobreposição de camadas significativas, Tiradentes ocuparia um espaço de distinção no que se refere à Inconfidência Mineira. O período republicano teria se encarregado de criar um símbolo ajustável ao sistema político que se impunha, sem contudo desestabilizar a sociedade através de um modelo inspirador de rebeliões. Sob essas condições, Tiradentes foi escolhido por trazer, ao mesmo tempo, a síntese do nacionalismo brasileiro e a sombra da derrota, o que muito convinha aos republicanos.

Além disso, ainda para Carvalho (2006), o caráter popular de Tiradentes, acrescido de sua patente militar e de seu posicionamento no centro econômico do país, foi fundamental na exploração dessa personagem histórica. Nessa perspectiva, a imagem do herói teria sido aos poucos sendo moldada segundo parâmetros políticos e morais demarcados, sendo posteriormente difundida para a coletividade. Nesse entendimento, teria sido destacada também a religiosidade do alferes, o que deu origem a uma constante comparação entre a sua figura e a de Cristo. No âmbito das artes, segundo Carvalho (2006), essa ligação teria sido ressaltada a partir dos relatos do historiador Noberto de Souza Silva², corroborados pela memória popular e pela apropriação política da imagem de Tiradentes. Nossas obras de análise, sobre as quais falaremos mais tarde, têm em certa medida o peso dessa reelaboração discursiva. O quadro de Pedro Américo traz em uma de suas facetas essa possibilidade de interpretação. Em o Romanceiro da Inconfidência, embora essa vertente seja mais esvanecida, também é possível de se encontrar certos traços dessa postura.

Com base nessas reflexões, podemos dizer que sob a aura dessa pretensa "naturalidade", Tiradentes é hoje visto como um mártir e não uma personagem da História Brasileira. Assim, o herói alcança a categoria de mito nacional, abrangendo sob seu domínio uma variedade de posturas ideológicas que ultrapassam em muito sua esfera inicial. O registro da memória coletiva, então, passou a contemplar toda essa diversidade de referências.

\footnotetext{
${ }^{2}$ SILVA, Joaquim Noberto de Souza, historiador brasileiro autor de História da Conjuração Mineira: estudos sobre as primeiras tentativas para a independência nacional
} 
ReVeLe - nº 2 - Jan/2011

Derrida (2001), nesse sentido, aponta para o poder do arquivo em acobertar e em abranger toda uma variedade de elementos em suas dimensões ${ }^{3}$. Essa característica aglutinadora, em nossa opinião, já evidenciaria a vocação fundadora do arquivo (estabelecer a origem, o princípio das coisas) e a sua propriedade organizadora (de ordem, de lugar de comando), vertentes indissociáveis que determinariam a existência do arquivo, segundo esse pesquisador. Nesse encontro, o arquivo manteria sempre uma tendência conciliadora, o que Derrida denominou de princípio de consignação do arquivo. Para ele,

A consignação tende a coordenar um único corpus em um sistema ou uma sincronia na qual todos os elementos articulam a unidade de uma configuração ideal. Num arquivo, não deve haver dissociação absoluta, heterogeneidade ou segredo que viesse a separar (secernere), compartimentar de modo absoluto. O princípio arcôntico do arquivo é também um princípio de consignação, isto é, de reunião. (DERRIDA, 2001, p. 14)

Partindo dessa categoria teórica, podemos inferir que a Inconfidência Mineira, nos moldes que tomou esse movimento, se organiza por esses parâmetros ao ultrapassar em muito sua dimensão histórica. Todos os componentes que lhe deram corpo no imaginário coletivo, especialmente a consagração de Tiradentes como herói nacional, encontram-se associados ao fato real, tornando difícil a desvinculação entre essas instâncias. Nota-se, portanto, a relevância da força normativa e discursiva da ideologia republicana, que aos poucos foi capaz de direcionar a formação do arquivo da Inconfidência Mineira.

É frente a essa realidade que tanto Cecília Meireles quanto Pedro Americo trabalham artisticamente o assunto. Cada qual irá, a sua maneira, apresentar uma releitura multifacetada que permite ao leitor/observador a apreensão de várias versões da Inconfidência Mineira, dando seus adendos à realidade histórica. Essa modalidade de acréscimo, que modifica mas não desarma o discurso pré-existente, torna-se um suplemento na medida em que "é um extra desnecessário, adicionado a algo completo em si mesmo, mas o suplemento é

\footnotetext{
${ }^{3}$ DERRIDA, Jacques. O Mal do arquivo: uma impressão freudiana. Tradução de Cláudia de Moraes Rego. Rio de Janeiro: Relume Dumará, 2001
} 
ReVeLe - nº 2 - Jan/2011

adicionado a completar, e a compensar uma lacuna no que deveria ser completa em si mesmo"4. A seguir, procuraremos apontar as particularidades dos trabalhos de Pedro Americo e Cecília Meireles, dedicando especial atenção para o modo como eles lidam com as dualidades levantadas pela memória da Inconfidência Mineira.

\section{A VISITA DE CECÍLIA MEIRELES AO ARQUIVO DA INCONFIDÊNCIA MINEIRA}

Cecília Meireles, poetisa consagrada por suas obras de um lirismo peculiar, publica em 1953 a série de poemas intitulada Romanceiro da Inconfidência, trabalho dedicado a recontar literariamente o episódio histórico da Inconfidência Mineira. Dividido em três partes, o livro é constituído de romances, pequenos poemas que abordam algum aspecto da conjura, podendo eles ser os integrantes do movimento, personagens que existiram à época ou mesmo o ambiente em que tudo se desenrolou. Zagury $(1973)^{5}$ destaca a importância da escolha dessa forma poética no entendimento da obra como um todo, demonstrando a união dos estilos épicos e lírico. Segundo a pesquisadora, os romances conservariam vestígios da narrativa épica aliando com a carga emocional caractetéristica do gênero lírico. No domínio popular, esse tipo de poema teria seu aspecto épico esvanecido, uma vez que se quebraria a ordenação narrativa típica desse gênero. Em compensação, os elementos líricos e/ou dramáticos seria ressaltados, dominando a composição.

Os processos que guiam a predominância dos gêneros lírico e dramático no romanceiro meireliano são diversos porém unívocos. Primeiramente, há-de se notar aquilo que Zagury (1973) chamou de "impossibilidade da epopeia da Inconfidência": o fracasso do movimento e da morte de Tiradentes, o herói, vai de encontro ao espírito de superação sobre-humana que rege esse tipo de discurso. Em segundo lugar, a necessidade de se reconstruir todo o complexo que envolveu a

\footnotetext{
${ }^{4}$ CULLER, Jonathan. Sobre a desconstrução: teoria e crítica do pós-estruturalismo. Rosa dos tempos: Rio de Janeiro, 1997, p.119

5 ZAGURY, Eliane. Cecília Meireles: notícias biográficas, estudo crítico, antologia, discografia, partituras. Petrópolis: Vozes, 1973.
} 
ReVeLe - nº 2 - Jan/2011

insurreição, com suas personagens, ambientes e tramas, leva a poetisa a distribuir as vozes da narrativa, numa clara correspondência aos diálogos teatrais. Entretanto, é patente a sua insuficiência para a poetisa, que deseja, à sua maneira, fazer jus à Inconfidência Mineira:

Assim, a primeira tentação (...) seria reconstituir a tragédia na forma dramática em que foi vivida, redistribuindo a cada figura o seu verdadeiro papel. Mas se isso bastasse, os documentos oficiais com seus interrogatórios e respostas, suas cartas, sentenças e defesa realizariam a obra de arte ambicionada, e os fantasmas sossegariam, satisfeitos. (MEIRELLES, 2005, p. XXIV)

Somente a expressão lírica das emoções diante da gravidade dos acontecimentos é capaz de fazer o adendo à História, trazendo à tona o que escapa ao julgamento de veracidade com que tradicionalmente se pautava essa disciplina. ${ }^{6}$ Com essa mudança de perspectiva, as personagens centrais da trama, os Inconfidentes, abandonam a condição impessoal porém imperativa de heróis canonizados para serem poeticamente observados como seres humanos, dotados de sonhos, vontades e, irremediavelmente, sofrimento:

\footnotetext{
- Minas da minha esperança, Minas do meu desespero! Agarram-me os soldados, como qualquer bandoleiro. Vim trabalhar para todos, e abandonado me vejo. Todos tremem. Todos fogem. A quem dediquei meu zelo? (MEIRELES, 2005, p. 107)
}

\begin{abstract}
Nessa abordagem, a carga emocional depositada nessas personagens/heróis provoca um sentimento de empatia no leitor da obra, especialmente por Tiradentes, que de diversas formas foi privilegiado pelo discurso histórico e pela memória coletiva como a figura mais emblemática do movimento. Ainda corrobora com essa postura lírica a manifestação de valores atemporais,

6 CUNHA, Karla Pereira. Contribuições da moderna crítica literária no estudo da história:suas assimilações nas obras de Gabriel Garcia Márquez e Octavio Paz. In: Gabriel Garcia Márquez e Octavio Paz: a questão da identidade ibero-americana en Cien años de soledad e El laberinto de la soledad. 2007. Dissertação (Mestrado em História) - Instituto de Ciências Humanas,UFJF, Juiz de Fora, 2007, p- 21-55.
\end{abstract}


ReVeLe - nº 2 - Jan/2011

humanos, de que os Inconfidentes se tornam porta-vozes, extrapolando o papel histórico a eles atribuído. Em um dos romances mais belos de toda a obra, o "Romance LIX ou Da reflexão dos justos", um narrador desconhecido, possivelmente um membro do povo que reconhece a pertinência da posição de Tiradentes e o peso da sentença que lhe foi dada, entrelaça um pensamento sobre a natureza humana com o destino do Inconfidente:

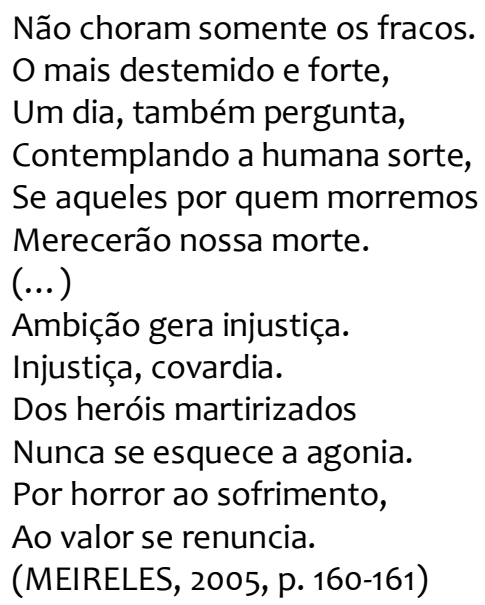

Dessa forma, segundo Silva (2008)7, a predominância do gênero lírico propiciaria a suplementação do arquivo da Inconfidência Mineira ao romper com um olhar objetivo na formação da memória. Entretanto, há-de se observar, no interior do Romanceiro da Inconfidência, um outro movimento que se associa à quebra da aura sobre-humana dos Inconfidentes: a reiteração da imagem nacionalista e heróica de Tiradentes elaborada no período republicano de nossa história.

Se, a princípio, a coexistência desses dois pontos de vista ideologicamente distintos pode aparentar ser uma contradição meireliana, ao nos determos sobre eles percebemos que eles complexificam o Romanceiro da Inconfidência ao demonstrar as diversas facetas do mártir. Além disso, ressaltamos que a visita de Cecília Meireles ao arquivo da Inconfidência Mineira trata de uma suplementação, e não um rompimento. O caráter dual seria, para Silva (2008), imanente ao arquivo, que portaria o ímpeto da manutenção da tradição e, ao

\footnotetext{
${ }^{7}$ SILVA, Denise de Fátima Gonzaga da. Cecília Meireles e herói Inconfidente: Um encontro da poética moderna com os arquivos da História Brasileira.2008. Dissertação (Mestrado em Teoria da Literatura) - Faculdade de Letras,UFJF, Juiz de Fora, 2008.
} 
ReVeLe - nº 2 - Jan/2011

mesmo tempo, da renovação. Evidentemente, o peso da figura criada pelos republicanos, que engatilha uma série de valores nacionalistas, heróicos e, sobretudo, identitários no repertório coletivo exerce sua influência sobre a poetisa. A esses fatores soma-se, por fim, a preocupação com a nacionalidade e a identidade brasileiras, apontada por Silva (2008) como preocupações comuns tanto da República da Espada como do Modernismo, movimento que a poetisa se insere.

Em Romanceiro da Inconfidência, a reafirmação da ideologia positivista se dá através de suas frentes. Em primeiro lugar, temos a indubitável vinculação entre Cristo e Tiradentes e, consequentemente, do martírio cristão e do Inconfidente. A sacralidade da sua missão (romper com as amarras da exploração) se assemelha bastante com a tarefa cristã de salvar os homens do pecado, bem como o sacrifício em nome de uma comunidade e de um ideal:

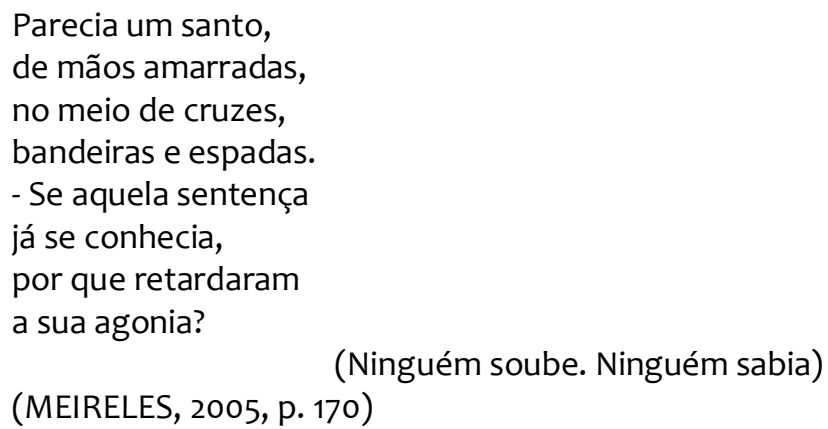

Em segundo lugar, ambos compartilham de uma certa visão paternalista do povo, como se somente através deles o conhecimento supremo, a liberdade, seria alcançado. Para Cristo, a liberdade estaria em um outro mundo, além do visível; no caso de Tiradentes, contudo, esse conceito é irremediavelmente associado à Inconfidência Mineira e a separação com Portugal. Assim, nos anos da primeira república, Tiradentes foi tomado como o símbolo da liberdade, que somente os republicanos, após cem anos, poderiam verdadeiramente corresponder. Essa ligação entre dois movimentos distintos acabou, por interesses políticos, transferido as qualidades atribuídas ao herói Inconfidente para a República: ressaltar suas virtudes acabava por, indiretamente, legitimar o grupo republicano e desprestigiar a monarquia. Cecília Meireles retoma essa visão de Tiradentes como o estandarte da liberdade em passagens como: 
ReVeLe - nº 2 - Jan/2011

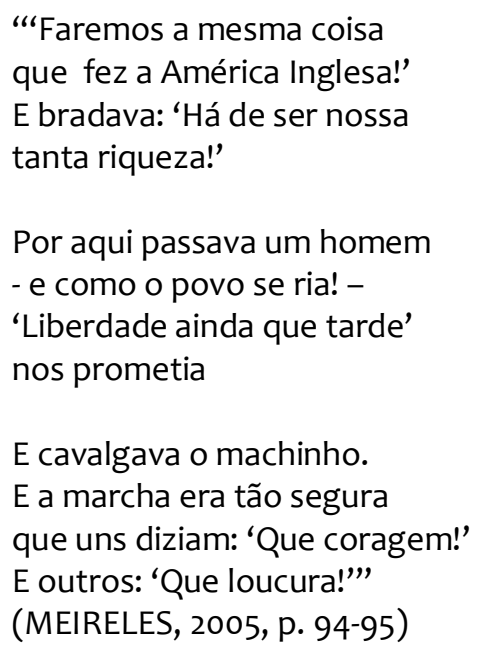

Como vimos, em Romanceiro da Inconfidência, existe a coexistência de dois parâmetros cujo enlace ao longo da obra contribui para o enriquecimento do arquivo e para a reformulação da visão canonizada pela história. A literatura, como o fazem as artes em geral, assume a tarefa de debater o discurso tradicional, acrescentando sua versão crítica. No caso estudado, isso se dá com a humanização dos heróis e com a consequente participação emotiva suscitada no leitor. Essa suplementação do arquivo da Inconfidência Mineira é explicada pela própria poetisa:

\footnotetext{
Nesse ponto descobrem-se as distâncias que separam o registo histórico da invenção poética: o primeiro fixa determinadas verdades que servem à explicação dos fatos; a segunda, porém, anima essas verdades de uma força emocional que não apenas comunica fatos, mas obriga o leitor a participar intensamente deles, arrastando no seu mecanismo de símbolos, com as mais inesperadas repercussões. (MEIRELES, 2005, p. XXIV- XXV)
}

Semelhante processo ocorre com a retomada do assunto pelo pintor Pedro Americo no quadro Tiradentes Esquartejado. É o que abordaremos a seguir. 
ReVeLe - nº 2 - Jan/2011

\section{A VISITA DE PEDRO AMERICO AO ARQUIVO DA INCONFIDÊNCIA MINEIRA}

Pedro Americo, célebre pintor de Independência ou Morte (1887-1888), produziu em 1893 um quadro denominado Tiradentes Esquartejado.

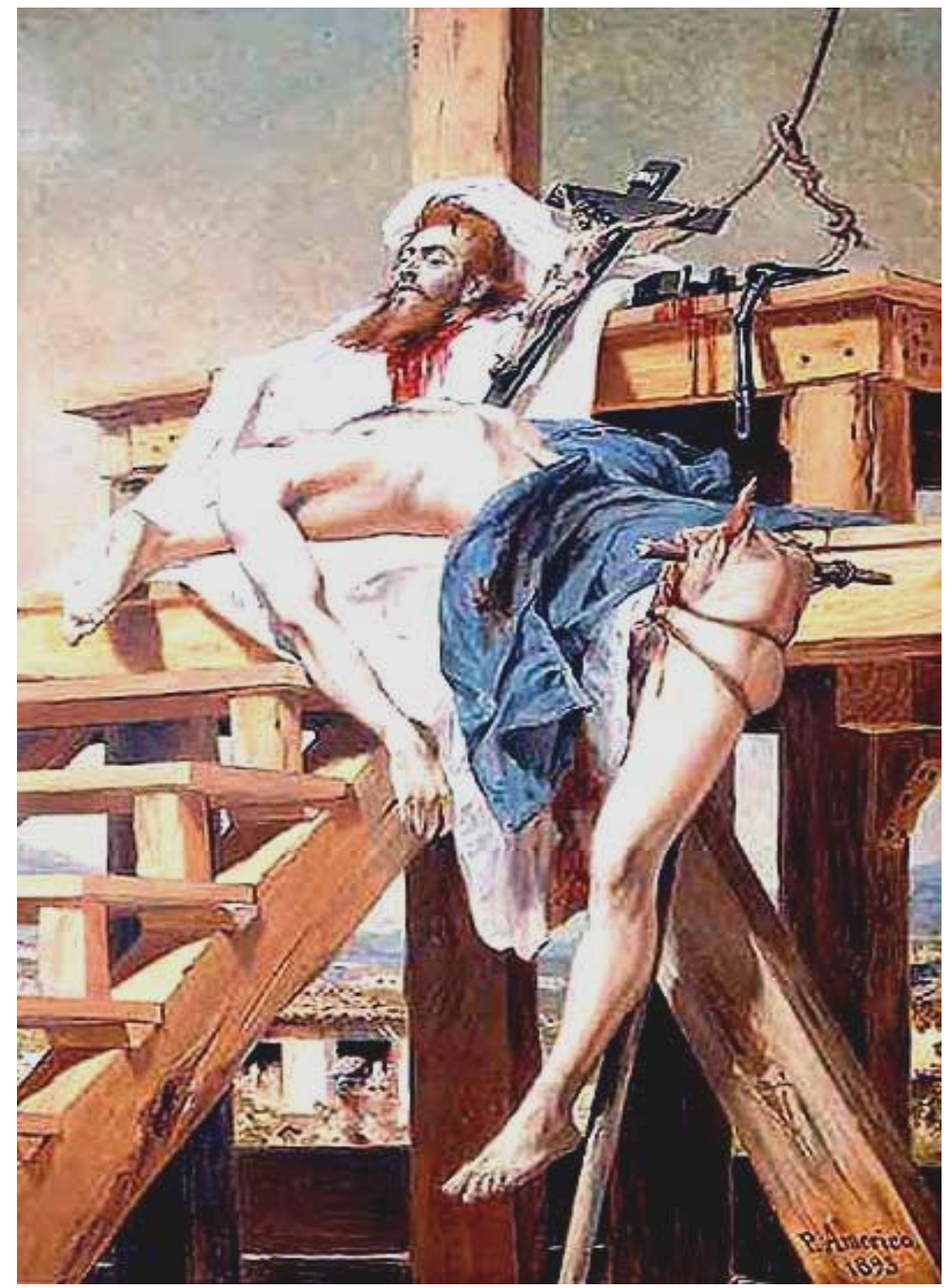

AMERICO, Pedro: Tiradentes Esquartejado, 1893 . Óleo sobre tela, $270 \times 180 \mathrm{~cm}$ Juiz de Fora, Museu Mariano Procópio

Nessa obra, Pedro Americo retrata o herói Inconfidente após a sua sentença, ainda no cadafalso, mas já com o corpo desmembrado. A parte inferior da tela é dominada pela brutalidade da carne exposta, especialmente a perna esquerda trespassada por pedaços de madeira. Segue-se ainda, no centro da obra, o tronco e a perna direita de Tiradentes, partes dispostas sobre um pano branco que contém 
ReVeLe - nº 2 - Jan/2011

vestígios de sangue. Por fim, no plano superior de Tiradentes Esquartejado, encontramos a cabeça do mártir, ladeada por um crucifixo, uma corda e um grilhão. Ao fundo, vemos algumas pessoas nas sacadas de uma casa humilde, bem como as montanhas características de Minas Gerais. Para Pereira (1999) ${ }^{8}$, a superposição de planos do quadro apresenta um choque entre a uma cena da vida cotidiana e o peso da morte do herói, que suplanta qualquer temporalidade.

A representação de Tiradentes, de princípio, é indissociável do martírio cristão. À semelhança das imagens recorrentes de Cristo, o herói possui cabelos e barba castanhos, passando serenidade em seu semblante. O crucifixo reforça essa ligação, numa comparação quase direta entre essas duas personagens; o grilhão e a corda são como lembretes do sacrifício de Tiradentes e de seu sofrimento em prol da liberdade. O tom grave que Pedro Americo dedica a figuras históricas em seus quadros é mantido na perspectiva que o observador tem de Tiradentes. Ele é convidado a olhá-lo de baixo para cima, reafirmando a posição superior do mártir. Christo $(2005)^{9}$ também argumenta que a disposição dos membros esquartejados sugerida na tela remonta a composição do corpo, o que daria à carne vilipendiada algum sentido de humanidade ainda latente. Mais ainda, o braço direito, que descansa sobre o cadafalso, teria uma clara intertextualidade com as obras Pièta (1497-1500), de Michelangelo, e Deposição de Cristo (1602-1604), de Caravaggio, o que corroboraria com o entrelaçamento das trajetórias de Tiradentes e Cristo.

Essa visão da obra, que foi a mais divulgada e aceita, servia plenamente aos ideais republicanos. Por muito tempo, acreditou-se que Pedro Americo estava apoiando ideologicamente esse novo sistema de governo, principalmente se considerarmos a proximidade entre as datas da Proclamação da República (1889) e da elaboração do quadro (1893). Entretanto, o estudo de Christo (2005) apontou dois fatores que sustentam que Tiradentes Esquartejado é uma suplementação ao arquivo da Inconfidência Mineira, como o é o Romanceiro da Inconfidência: a rejeição da tela na ocasião de seu lançamento, bem como os problemas de circulação de sua

\footnotetext{
${ }^{8}$ PEREIRA, Terezinha Maria Scher. Por quais roteiros se visita uma bienal? In: PEREIRA, Maria Luiza Scher. (org.) Ipotesi: Revista de estudos literários. Juiz de Fora: EDUFJF, v.3, n.2, jul./dez. 1999

9 CHRISTO, Maraliz de Castro Vieira. Pintura, história e heróis no século XIX: Pedro Americo e Tiradentes Esquartejado. 2005. 323f. Tese (Doutorado em História) - Instituto de Filosofia e Ciências Humanas, UNICAMP, Campinas, 2005.
} 
ReVeLe - nº 2 - Jan/2011

imagem e a inserção da obra numa série sobre a Conjuração Mineira e na pintura histórica da segunda metade do século XIX.

Segundo a pesquisadora, a primeira exposição de Tiradentes Esquartejado, em 1983 no Rio de Janeiro, não foi bem sucedida, já que a crítica da época teria o considerado agressivo à imagem de Tiradentes. Assim sendo, ele teria sido vendido à Câmara Municipal de Juiz de Fora e posteriormente doado ao Museu Mariano Procópio, de onde nunca teria saído até 1998. No que tange a produção do pintor, Pedro Americo teria sido lembrado pelas suas telas do período imperial, como Independência ou Morte (1887-1888) e Batalha de Avahy (1872-1877). Tiradentes Esquartejado teria sido considerado uma obra menor do pintor até 1965 , quando o herói teria sido alçado a categoria de patrono do Brasil durante o regime militar. Nesse período, com a circulação livre de obras como Grandes personagens da nossa história ${ }^{10} \mathrm{e}$ a enciclopédia da História do Brasil $^{11}$, a tela teria sido finalmente divulgada. Pela força do quadro, Tiradentes Esquartejado teria finalmente entrado para o repertório popular das imagens que concernem a Inconfidência Mineira, passando, portanto, incólume à primeira República. Sua divulgação tardia indica, dessa forma, muito mais uma revitalização do ideal republicano pela Ditadura Militar (1964-1988) do que um envolvimento direto de Pedro Americo com esse movimento.

Outro aspecto para qual Christo (2005) chamou atenção é que Tiradentes Esquartejado originalmente seria inserido numa série de telas sobre a Conjuração Mineira, sendo a última obra de cinco quadros. A ele antecederiam $A$ cena idílica de Gonzaga a bordar a fio de ouro o vestido nupcial de sua Marília, A mais importante das reuniões dos conjurados, A cena da constatação de óbito, passada diante do cadáver de Cláudio Manuel da Costa e A prisão de Tiradentes em casa da antiga rua dos Latoeiros. A única tela a ser executado seria Tiradentes Supliciado, posteriormente chamada Tiradentes Esquartejado. Embora não tenhamos a série realizada, os títulos das obras contribuem para a compreensão do propósito de Pedro Américo. O conjunto das telas pretendem, visivelmente, contar o desenrolar da Inconfidência Mineira, focando-se na derrota dos Inconfidentes.

\footnotetext{
${ }^{10}$ Grandes personagens da nossa história. Editora Abril. $1^{\mathrm{a}}$ ed. 1969.

${ }^{11}$ História do Brasil. São Paulo: Editora Bloch, 1972.
} 
ReVeLe - nº 2 - Jan/2011

Para Christo (2005), o pintor, influenciado pelo trabalho de Noberto de Souza Silva (1873), teria escolhido a cena do poeta Tomás Antônio Gonzaga para mostrar o descompasso entre o considerado líder da conjuração e amante dedicado que ele teria sido. A imagem que retemos da personagem seria a do poeta e não do Inconfidente, o que nos levaria a questionar a organização do grupo. Esse ponto seria novamente abordado no segundo quadro, já que no estudo encontrado pela estudiosa Tiradentes aparece na reunião anterior à derrama discursando, como o líder do movimento, enquanto Gonzaga é mero espectador. A presença de Silvério dos Reis, o traidor da Inconfidência Mineira, já apontaria para a ruína dos Inconfidentes, em especial, de Tiradentes. A partir da terceira tela, o fracasso se tornaria evidente. A morte de Cláudio Manuel da Costa seria cercada de incertezas, uma vez que seria impossível elucidar se o poeta cometeu suicídio ou teria sido assassinado na prisão. De qualquer forma, para a pesquisadora, a escolha desse momento demonstraria como os Inconfidentes estavam despreparados, ressaltando a facilidade que o governo português teve em dominar a rebelião. Por fim, a prisão de Tiradentes teria apenas a função de preparar o espectador para a forte cena do esquartejamento e da constatação final e irrevogável do aniquilamento da Inconfidência Mineira.

O que é essencial notar sobre a compreensão de Tiradentes Esquartejado como um elemento dentro de uma série maior sobre a conjuração é a visão sobre o fato histórico. Ao contrário do que se pensava, o pintor inculca a constatação da falência do movimento desde o seu início, o que abala a imagem heróica dos Inconfidentes. Seus ideais parecem frágeis, quase pueris, e a sua proposta de ação inconsequente. Nas palavras da pesquisadora,

(...) A série fornece maior coerência ao quadro. Ela é fundamental por desvendar o julgamento do artista a propósito da Conjuração Mineira: um movimento débil internamente, condenado ao fracasso antes mesmo da sua repressão. O corpo despedaçado, sem mais vontade própria, alvo da ação de outrem, seria, não apenas a denúncia da violência, mas o ápice do sentimento de fracasso e solidão, presente em toda a série. (CHRISTO, 2005, p. 132). 
ReVeLe - nº 2 - Jan/2011

Nesse sentido, Christo (2005) defende que Pedro Americo está de acordo com a pintura histórica dos fins do século XIX. A partir desse período, os pintores dessacralizariam a figura clássica do herói, retratando-o vencido e impotente, principalmente após a Guerra Franco-Prussiana. Mostrar a o corpo fracionado de Tiradentes, então, daria ênfase não a força repressora portuguesa, mas sim a falta de sustentação do próprio movimento, além de repercutir o descrédito que a figura do herói passava na época de elaboração do quadro.

Assim, à maneira de Romanceiro da Inconfidência, estamos diante de um entrecrusamento de matizes de significação em uma mesma obra. Pedro Americo dialoga com a personalidade do herói Tiradentes, tão difundida pelos republicanos positivistas, mas ao mesmo tempo cria uma adversativa à consagração de Tiradentes ao expor, violentamente, o fracasso da Inconfidência Mineira através do mártir esquartejado. Como vimos, ao complementar o arquivo institucionalizado da Inconfidência Mineira, Pedro Americo o suplementa, trazendo novas informações que o acrescentam.

De forma alguma, apesar da aparente contradição, essas informações invalidam uma a outra: elas indicam a dificuldade de abordagem de uma personagem tão complexa como Tiradentes, que joga com valores como liberdade e nacionalidade. Sua presença emblemática na formação na identidade nacional e mineira traz consigo a aura do mártir, e ao negá-la completamente, tanto Cecília Meireles quanto Pedro Americo acabariam minando de certa forma o conjunto de valores que nos fazem brasileiros. Contudo, a suplementação de Romanceiro da Inconfidência e Tiradentes Esquartejado abre a possibilidade do repensar, infiltrando dentro do espaço anónico do arquivo da Inconfidência Mineira, num ato subversivo, a própria argumentação que enfraquece a sua afirmativa.

\section{REFERÊNCIAS}

AMERICO, Pedro. Tiradentes esquartejado, 1893. Óleo sob tela, 270 x $180 \mathrm{~cm}$. Juiz de Fora, Museu Mariano Procópio. 
CARVALHO, Aline Fonseca. A conveniência de um legado adequável: representações de Tiradentes e da Inconfidência Mineira durante a ditadura militar. 2006. 150 f. Dissertação (Mestrado em História)- Faculdade de Filosofia e Ciências Humanas, UFMG, Belo Horizonte, 2006.

CHRISTO, Maraliz de Castro Vieira. Pintura, história e heróis no século XIX: Pedro Americo e Tiradentes Esquartejado. 2005. 323f. Tese (Doutorado em História) Instituto de Filosofia e Ciências Humanas, UNICAMP, Campinas, 2005.

CULLER, Jonathan. Sobre a desconstrução: teoria e crítica do pós-estruturalismo. Rosa dos tempos: Rio de Janeiro, 1997.

CUNHA, Karla Pereira. Contribuições da moderna crítica literária no estudo da história:suas assimilações nas obras de Gabriel Garcia Márquez e Octavio Paz. In: Gabriel Garcia Márquez e Octavio Paz: a questão da identidade ibero-americana en Cien años de soledad e El laberinto de la soledad. 2007. Dissertação (Mestrado em História) - Instituto de Ciências Humanas,UFJF, Juiz de Fora, 2007, p. 21-55.

DERRIDA, Jacques. Mal de arquivo: uma impressão freudiana. Trad.. Cláudia de Moraes Rego. Rio de Janeiro: Relume Dumará, 2001.

MEIRELES, Cecília. Romanceiro da inconfidência. 3.ed. Rio de Janeiro: Nova Fronteira, 2005 .

PEREIRA, Terezinha Maria Scher. Por quais roteiros se visita uma bienal? In: PEREIRA, Maria Luiza Scher. (org.) Ipotesi: Revista de estudos literários. Juiz de Fora: EDUFJF, v.3, n.2, jul./dez. 1999

SILVA, Denise de Fátima Gonzaga da. Cecília Meireles e herói Inconfidente: Um encontro da poética moderna com os arquivos da História Brasileira.2008. Dissertação (Mestrado em Teoria da Literatura) - Faculdade de Letras, UFJF, Juiz de Fora, 2008.

ZAGURY, Eliane. Cecília Meireles: notícias biográficas, estudo crítico, antologia, discografia, partituras. Petrópolis: Vozes, 1973. 